\title{
Disciplina De Estatística Na Matriz Curricular Dos Cursos De Licenciatura Em Matemática No Brasil
}

\author{
Discipline Of Statistics In The Curricular Matrix Of The Mathematics Degree Courses \\ In Brazil
}

\author{
Márcio Urel Rodrigues* \\ Universidade do Estado de Mato Grosso - UNEMAT \\ Luciano Duarte da Silva** \\ Instituto Federal de Educação, Ciência e Tecnologia de Goiás - IFG
}

\begin{abstract}
Resumo
Nesta pesquisa, objetivamos compreender como as disciplinas de Estatística estão estruturadas na Matriz Curricular dos cursos de licenciatura em Matemática em atividade no Brasil. realizamos uma pesquisa qualitativa na modalidade documental, por meio da análise de 190 Projetos Pedagógicos de Cursos (PPCs) de licenciatura em Matemática de todas as regiões geográficas do Brasil. Como referencial teórico, recorremos a diversos pesquisadores que abordam a importância da Formação Estatística nas licenciaturas em Matemática. Para analisar os dados, utilizamos alguns procedimentos da Análise de Conteúdo na perspectiva elucidada por Bardin (1977), a qual nos proporcionou constituir quatro Categorias de Análise que representam os aspectos centrais da pesquisa: (i) Estatística Descritiva; (ii) Estatística Inferencial; (iii) Análise Combinatória e Probabilidade; (iv) Ensino de Estatística na Educação Básica. Essas categorias de análise foram interpretadas por meio de um movimento dialógico entre os dados, o referencial teórico, o objetivo da pesquisa, bem como as nossas percepções. A análise interpretativa dessas categorias nos permitiu compreender que, apesar de existirem disciplinas de conhecimentos de Estatística em 97\% das matrizes curriculares dos PPCs de licenciatura em Matemática no Brasil, elas privilegiam a abordagem conceitual em detrimento de uma abordagem mais relacionada ao conhecimento pedagógico dos conteúdos de Estatística que os futuros professores trabalharão nas escolas da Educação Básica. Assim sendo, os resultados da presente pesquisa apontam para a necessidade de uma readequação das disciplinas de Estatística pelos Núcleos Docentes Estruturantes (NDEs), convergente para a futura prática docente dos licenciados em Matemática nos ensinos fundamental e médio.
\end{abstract}

Palavras-chave: Estatística, Licenciatura em Matemática, Projetos Pedagógicos de Cursos.

\begin{abstract}
In this research, we aim to understand how the Statistics disciplines are structured in the Curricular Matrix of the Degree in Mathematics courses in activity in Brazil. We conducted a qualitative research in the documentary modality, through the analysis of 190 Pedagogical Projects of Courses (PPCs) of Degree in Mathematics of all the geographic regions of Brazil. As a theoretical reference, we have

\footnotetext{
* Doutor em Educação Matemática pela Unesp - Rio Claro/SP. Docente do Programa de Pós-Graduação em Ensino de Ciências e Matemática - PPGCEM, e Professor Adjunto da Universidade do Estado de Mato Grosso UNEMAT - Barra do Bugres/MT, Brasil. E-mail: marcio.rodrigues@unemat.br

** Doutor em Educação Matemática pela Unesp - Rio Claro/SP. Docente do Mestrado Profisssional em Educação para Ciências e Matemática - IFG - Jataí/GO. Professor do Instituto Federal de Educação Ciências e Tecnologia - IFG - Goiânia/GO, Brasil. E-mail: lucianoduartee@gmail.com
} 
recourse to several researchers that address the importance of Statistical Training in the Degree in Mathematics. To analyze the data, we used some procedures of the Content Analysis in the perspective elucidated by Bardin (1977), which provided us with four Categories of Analysis that represent the central aspects of the research: (i) Descriptive Statistics; (ii) Inferential Statistics; (iii) Combinatorial Analysis and Probability; (iv) Teaching Statistics in Basic Education. These categories of analysis were interpreted through a dialogical movement between the data, the theoretical reference, the research objective, as well as our perceptions. The interpretative analysis of these categories allowed us to understand that although there are statistical knowledge disciplines in $97 \%$ of the curricular matrices of the Degree in Mathematics PPCs in Brazil, they privilege the conceptual approach to the detriment of an approach more related to the pedagogical knowledge of the contents of Statistics that future teachers will work in Basic Education schools. Thus, the results of the present research point to the need for a reshaping of the disciplines of Statistics by the Teaching Core Structures (NDEs) convergent for the future teaching practice of Mathematics graduates in primary and secondary education.

Keywords: Statistic, Degree in Mathematics, Pedagogical Projects of Courses, Content Analysis.

\section{Introdução}

No presente artigo, apresentamos os resultados de uma pesquisa qualitativa na abordagem documental envolvendo a formação estatística do futuro professor na perspectiva dos Projetos Pedagógicos dos Cursos (PPCs) de licenciatura em Matemática no Brasil. Esta pesquisa está vinculada a dois projetos de pesquisa institucionalizados.

O primeiro intitulado: Investigação Curricular das Disciplinas presentes nos cursos de Licenciatura em Matemática no Brasil, desenvolvido pelo segundo autor no Instituto Federal de Educação (IFG - Campus Goiânia), com o objetivo de: compreender como estão estruturadas as disciplinas de Conteúdo Específico, Educação e Educação Matemática dos cursos de licenciatura em Matemática no Brasil. O segundo intitulado: Conhecimentos Necessários à Docência e a Formação Inicial de Professores de Matemática no Estado de Mato Grosso, desenvolvido pelo primeiro autor na Universidade do Estado de Mato Grosso (UNEMAT Campus de Barra do Bugres), com o objetivo de investigar a maneira como os conhecimentos necessários à docência estão presentes nos cursos de Licenciatura em Matemática no Estado de Mato Grosso.

Destacamos a importância de o futuro professor de Matemática dominar os conteúdos relacionados à Estatística para ensinar Matemática na Educação Básica (conforme amplamente evidenciado pela Base Nacional Comum Curricular). Assim sendo, na nossa visão, cabe aos cursos de formação inicial de professores de Matemática trabalhar com os referidos conhecimentos de Estatística para que eles possam desenvolver, em sua prática pedagógica, um ensino de Matemática de qualidade.

Dessa forma, por se tratar de uma investigação das instituições brasileiras em que as disciplinas de Estatística estão sendo pensadas e planejadas pelos Núcleos Docentes 
Estruturantes (NDEs) dos cursos de licenciatura em Matemática no Brasil, esta pesquisa tornase peça fundamental para investigar qual tem sido a formação estatística do futuro professor de Matemática. Além disso, procuramos identificar a maneira como a formação conceitual em Estatística está presente na matriz curricular dos cursos de licenciatura em Matemática no Brasil, para proporcionar aos NDEs contribuições formativas e curriculares objetivando uma melhor estruturação das referidas disciplinas na formação inicial de professores em Matemática.

Como formadores de professores, atuantes em dois cursos de licenciatura em Matemática de duas instituições de ensino superior (IES) diferentes no Brasil, nosso interesse consiste em investigar, estudar e discutir questões e processos relacionados à formação inicial dos professores de Matemática. Desta maneira, acreditamos que o presente artigo auxiliará os cursos de licenciatura em Matemática no Brasil em seus processos constantes de (re)estruturação, fomentando discussões nos NDEs no interior de cada curso.

Como primeiro momento do artigo, realizamos uma fundamentação teórica a respeito da disciplina de Estatística na formação inicial de professores de Matemática. Em um segundo momento, apresentamos os aspectos metodológicos - opção metodológica, procedimentos utilizados para coletar e analisar os dados. Em um terceiro momento, a descrição e análise interpretativa dos dados, por meio de um movimento dialógico entre os dados e referenciais teóricos. Em um quarto momento, apresentamos as considerações finais e, logo após, registramos as referências.

\section{Estatística nas Licenciaturas em Matemática no Brasil}

Neste momento recorremos a diversos pesquisadores que abordam aspectos relacionados à importância da disciplina de Estatística para os processos de formação de professores de Matemática no Brasil.

Segundo Lopes (2008), a formação do futuro professor de Matemática na Educação Básica deve prever:

Um processo de ensino e aprendizagem de conteúdos que ocorra através da resolução de problemas, simulações e experimentos, os quais permitam ao profissional construir conhecimentos, à medida que estabelecer relações com informações adquiridas e com o domínio de diferentes linguagens e formas de expressão (Lopes, 2008, p. 71).

Para a referida autora, um dos maiores problemas relacionados ao ensino de Estatística e Probabilidade está na formação inicial dos futuros professores, ao afirmar que "um dos principais impedimentos ao ensino efetivo de probabilidade e estatística na Educação Básica 
refira-se à formação dos professores que ensinam matemática nesses níveis de ensino: educação infantil, ensino fundamental e ensino médio" (Lopes, 2008, p. 69).

Viali (2008), em sua pesquisa, objetivou verificar a presença e a carga horária destinada às disciplinas de Probabilidade e Estatística nos cursos de licenciatura em Matemática. Esse autor analisou uma amostra de 125 currículos, selecionados aleatoriamente de um total de 539 cursos existentes no Brasil. A conclusão desse trabalho foi que os tópicos relacionados à Probabilidade e à Estatística ocupam em média 2,5\% da carga horária total das licenciaturas em Matemática.

Assim sendo, o referido autor conclui afirmando que existe um verdadeiro descompasso entre a formação inicial do professor de Matemática e o que eles devem ensinar na Educação Básica, no que se refere aos temas de Probabilidade e Estatística. Em outro momento, Viali e Cury (2011, p. 4) declaram que um fator que influencia o ensino de Probabilidade e Estatística na Educação Básica é a formação nem sempre adequada, recebida por licenciados em Matemática, para trabalhar com os conteúdos dessa área, pois "As matrizes curriculares dos cursos de licenciatura em Matemática, em geral, não apresentam disciplinas de Probabilidade e Estatística ou, quando apresentam, englobam os conteúdos em uma única disciplina, compartilhada por cursos de outras áreas, como Engenharia”.

O estudo de Costa (2007) destaca as pesquisas brasileiras sobre educação estocástica na formação do professor de Matemática, por ter investigado a percepção dos professores em exercício na Educação Básica e dos formadores de professores no ensino superior com significativa produção científica, que atuam na formação inicial de professores de Matemática. Esses entrevistados revelam que reconhecem a existência de lacunas na formação docente, bem como problemas conceituais e epistemológicos nos livros didáticos.

Silva (2011) enfatiza que os conteúdos de Estatística e Probabilidade estão inseridos nas matrizes curriculares dos cursos de licenciatura em Matemática das IES pesquisadas, no entanto existem descompassos entre a formação inicial do professor de Matemática e as orientações curriculares para a Educação Básica, pois a preocupação com o domínio dos conteúdos específicos constitui-se como o foco das referidas disciplinas.

Para Lopes, Coutinho e Almouloud (2010), o ensino de conteúdos de Estatística não tem sido prioridade na escola, nem nos programas de formação inicial e continuada de professores que ensinam Matemática, apesar de vários documentos curriculares oficiais de diversos países enfatizarem a importância da Estatística para a construção da cidadania, pois é necessário que os alunos aprendam a selecionar, analisar e interpretar estas informações, para que possam 
tomar suas decisões.

Lopes (2013, p. 903) afirma que, no Brasil, diversas pesquisas têm sido desenvolvidas envolvendo a Educação Estatística, no entanto ressalta que "as pesquisas sobre a disciplina de estatística nos cursos de licenciatura em matemática ainda são poucas, mas já revelam aspectos importantes a serem refletidos”. Para a referida pesquisadora, é importante ampliar a discussão sobre a disciplina de Estatística para o curso de licenciatura em Matemática, visando atrelar as considerações sobre a formação necessária para o futuro professor de Matemática ao que têm revelado as pesquisas sobre Educação Estatística para a Educação Básica, pois:

\begin{abstract}
Os futuros professores precisam obter uma formação estatística que lhes permita pensar estatisticamente e aprender como promover o desenvolvimento do pensamento estatístico de seus futuros alunos. Para isso, a programação do curso de estatística para a licenciatura precisa ser revista e deve possibilitar aos alunos a apropriação de um conhecimento estatístico que vá além da resolução de problemas, ou seja, deve promover a realização de projetos e atividades de investigação e a problematização de situações diversas; e escolher adequadamente os processos de coleta, representação e análise de dados. (Lopes, 2013, p. 913).
\end{abstract}

Silva (2014), ao investigar a formação para o ensino da Estatística e Probabilidade, nos currículos dos cursos de licenciatura em Matemática no Brasil, por meio da análise das matrizes curriculares e ementários dos PPCs, concluiu que "Apesar da presença da Estatística e da Probabilidade como conteúdo, encontramos na estrutura curricular de alguns cursos, ainda incorporada, a visão da formação do professor para ensinar ser pautada exclusivamente no conhecimento conceitual" (Silva, 2014, p. 114).

Com base no referencial explicitado, percebemos a importância da formação em Estatística para o futuro professor de Matemática que atuará na Educação Básica. Assim sendo, também entendemos ser necessário repensarmos, enquanto formadores de professores de Matemática, a formação em Estatística nos cursos de licenciatura em Matemática no Brasil.

\title{
3 Aspectos Metodológicos
}

Utilizamos os pressupostos da pesquisa qualitativa, pois visamos descrever e interpretar as informações presentes nos PPCs de licenciatura em Matemática em atividade no Brasil em relação ao objeto investigado. A esse respeito, Creswell (2007, p. 186) afirma que a pesquisa qualitativa é fundamentalmente interpretativa, na qual o pesquisador faz uma interpretação dos dados, incluindo: “[...] o desenvolvimento da descrição de uma pessoa ou de um cenário, análise de dados para identificar temas ou categorias e, finalmente, fazer uma interpretação ou tirar conclusões sobre seu significado, pessoal e teoricamente".

Justificamos também a escolha pela pesquisa qualitativa pela nossa postura e anseio 
como pesquisadores atuantes em cursos de licenciatura em Matemática no Brasil. A esse respeito, Gatti (2002, p. 11) enfatiza que, "quanto mais próximas estiverem as pesquisas das realidades e contextos de atuação dos pesquisadores, estes adquirirão diversos conhecimentos, na perspectiva de apontar possíveis soluções para os problemas que os afligem”.

Considerando a origem dos dados e das várias modalidades de pesquisas qualitativas, definimos a documental como a mais apropriada, pois, Gil (2002, p. 45) enfatiza que "a pesquisa documental vale-se de materiais que não receberam ainda um tratamento analítico, ou que ainda não podem ser reelaborados de acordo com os objetos da pesquisa”.

\subsection{Procedimentos De Coleta De Dados - Corpus Da Pesquisa}

Considerando a perspectiva da pesquisa qualitativa segundo a estratégia documental, definimos os caminhos percorridos para a constituição do corpus da presente pesquisa. Para Bardin (1977, p. 96), “o corpus é o conjunto dos documentos tidos em conta para serem submetidos aos procedimentos analíticos”.

O corpus da presente pesquisa são os planos de ensino e os projetos pedagógicos de curso de Licenciatura em Matemática no Brasil. Tivemos acesso aos PPCs por meio de uma consulta aos cursos de Licenciatura em Matemática do Brasil na página institucional do Ministério da Educação (http://portal.mec.gov.br/index.php) e realizamos uma busca avançada no e-MEC, que pode ser acessado através do endereço eletrônico http://emec.mec.gov.br/

Além disso, obtivemos diversos PPCs dos dois projetos coordenados pelos autores do presente artigo. Com base nesse procedimento de coleta de dados, obtivemos 190 PPCs de cursos de licenciatura em Matemática de todos os estados do Brasil.

Com o corpus da pesquisa constituído, criamos um formulário no Google Docs com o objetivo de realizar o fichamento das informações referentes à disciplina de Estatística e Probabilidade presentes nos 190 PPCs. O formulário elaborado continha nove questões (cada questão representa uma determinada informação a ser retirada do PPC). Esse formulário foi respondido 190 vezes, o que corresponde ao total de documentos que compõem o corpus da pesquisa.

Para cada curso, retiramos as seguintes informações dos documentos (PPCs): (i) Categoria administrativa da IES (pública ou privada); (ii) Modalidade do curso (presencial, à distância ou semipresencial); (iii) Ano do PPC; (iv) Estado e região geográfica de origem dos IES; (v) Nomenclatura das disciplinas que abordam conteúdos de Estatística; (vi) Carga horária das disciplinas que abordam conteúdos de Estatística; (vii) Período em que as disciplinas estão 
dispostas na grade curricular; (viii) Ementas das disciplinas que abordam conteúdos de Estatística; e (ix) Bibliografia básica.

Utilizamos uma planilha no Excel para fichar e organizar as informações referentes aos conhecimentos de Estatística presentes nos PPCs como nos planos de ensino. Na planilha elaborada, cada coluna representa uma determinada informação, da qual explicitamos um exemplo no Quadro 1, a seguir:

Quadro 1 - Mapeamento do corpus da pesquisa.

\begin{tabular}{|c|c|c|c|c|c|c|c|c|}
\hline $\begin{array}{c}\text { Categori } \\
\mathrm{a} \\
\end{array}$ & $\begin{array}{l}\text { Modalid } \\
\text { ade } \\
\end{array}$ & $\begin{array}{c}\text { An } \\
\text { o }\end{array}$ & PPC & $\begin{array}{c}\text { Nomenclatu } \\
\text { ra }\end{array}$ & $\begin{array}{l}\mathrm{C} \\
\mathrm{H} \\
\end{array}$ & Sem & Ementa & Bibliografia Básica \\
\hline Pública & $\begin{array}{c}\text { Presenci } \\
\text { al }\end{array}$ & $\begin{array}{l}20 \\
13\end{array}$ & $\begin{array}{l}\text { Barra } \\
\text { do } \\
\text { Bugre } \\
\text { s/MT }\end{array}$ & $\begin{array}{c}\text { Estatística e } \\
\text { Probabilida } \\
\text { de }\end{array}$ & 60 & $5^{\circ}$ & $\begin{array}{l}\text { 1. Estatística } \\
\text { Descritiva; } \\
\text { 2. Representação } \\
\text { Tabular e Gráfica; } \\
\text { 3. Medidas de } \\
\text { tendência central; } \\
\text { 4. Medidas de } \\
\text { dispersão e de } \\
\text { variabilidade; } \\
\text { 5. Análise } \\
\text { Combinatória; } \\
\text { 6. Probabilidade. }\end{array}$ & $\begin{array}{l}\text { 1. Castro, L. V. Pontos de } \\
\text { Estatística. 15a Edição. } \\
\text { Editora Científica. } \\
\text { 2. Crespo, A. Estatística } \\
\text { Fácil. Editora Saraiva, 2001. } \\
\text { 3. Spiegel, M R. } \\
\text { Probabilidade e Estatística. } \\
\text { Coleção Shawun. São Paulo, } \\
\text { 1978. } \\
\text { 4. Bussab, W. O. Estatística } \\
\text { Básica. 5a edição. São Paulo, } \\
\text { 2003. }\end{array}$ \\
\hline
\end{tabular}

Fonte: Adaptado dos PPCs.

Com base no exemplo explicitado no Quadro 1, ressaltamos que realizamos a mesma descrição dos dados para cada um dos 190 PPCs das licenciaturas em Matemática, para mapear as características do contexto investigado. Através dessas informações filtradas dos PPCs, foram construídas algumas tabelas para melhor interpretação dos dados. Ressaltamos que em nenhum momento identificamos as instituições de ensino superior, nem os cursos de licenciatura em Matemática, por motivos éticos.

Das 190 IES que tiveram seus PPCs analisados, constatamos que 17\% são instituições privadas e $83 \%$ são instituições públicas; destas, $59 \%$ são federais e $24 \%$ são estaduais. $\mathrm{Na}$ Tabela 1, apresentamos a distribuição dos cursos de licenciatura em Matemática quanto à modalidade de ensino.

Tabela 1 - Modalidade dos cursos de licenciatura em Matemática

\begin{tabular}{ccc}
\hline Modalidade & Frequência & Frequência relativa \\
\hline Semipresencial & 02 & $1,10 \%$ \\
Distância & 32 & $16,80 \%$ \\
Presencial & 156 & $82,10 \%$ \\
\hline Total & 190 & $100 \%$
\end{tabular}

Observamos na Tabela 1 que cerca de $82,10 \%$ dos cursos investigados são na modalidade presencial, $16,80 \%$ são na modalidade a distância e 1,10\% são semipresenciais.

Em relação à região geográfica, apresentamos na Tabela 2, a seguir, a distribuição dos 
cursos de licenciatura em Matemática participantes da presente pesquisa.

Tabela 2 - Distribuição dos cursos de licenciatura em Matemática por região geográfica.

\begin{tabular}{ccc}
\hline Região geográfica & Frequência & Frequência relativa \\
\hline Sudeste & 65 & $34,20 \%$ \\
Nordeste & 45 & $23,70 \%$ \\
Sul & 32 & $16,80 \%$ \\
Centro-Oeste & 31 & $16,30 \%$ \\
Norte & 17 & $9,00 \%$ \\
\hline Total & 190 & $100,00 \%$ \\
\hline
\end{tabular}

Fonte: Dados da Pesquisa.

Conforme a Tabela 2, as regiões geográficas com maior frequência entre os cursos de licenciatura em Matemática investigados foi a região Sudeste, enquanto a região Norte foi a que apresentou a menor frequência absoluta de cursos investigados. Ressaltamos que conseguimos ter acesso a PPCs de licenciatura em Matemática de todos os estados do Brasil, bem como do Distrito Federal.

Continuando, apresentamos a seguir, na Tabela 3 , as nomenclaturas das disciplinas que abordam os conhecimentos de Estatística nos PPCs dos cursos de licenciatura em Matemática.

Tabela 3 - Nomenclaturas das disciplinas nas licenciaturas em Matemática no Brasil.

\begin{tabular}{ccc}
\hline Disciplina & Frequência & Frequência relativa \\
\hline Estatística e Probabilidade & 125 & $65,70 \%$ \\
Estatística & 38 & $19,80 \%$ \\
Introdução à Estatística & 20 & $10,50 \%$ \\
Não possui & 06 & $3,40 \%$ \\
Aprendizagem de Estatística no Ensino Fundamental e Médio & 01 & $0,60 \%$ \\
\hline Total & 190 & $100 \%$ \\
\hline Fonte: Dados da Pesquisa. &
\end{tabular}

Observando a Tabela 3, constatamos que os conhecimentos de Estatística são trabalhados, na maioria dos cursos de licenciatura em Matemática no Brasil, em disciplinas conjuntas de Estatística e Probabilidade. Outro aspecto relevante mostra um único PPC que procura desenvolver uma disciplina envolvendo conteúdos de Estatística com foco na prática docente dos futuros professores de Matemática na Educação Básica, pois discute, em sua ementa, aspectos como o papel do ensino de Estatística na Educação Matemática.

$\mathrm{Na}$ Figura 1, apresentamos os períodos em que as disciplinas que abordam os conhecimentos de Estatística foram ofertadas nos cursos de licenciatura em Matemática nos PPCs investigados. 


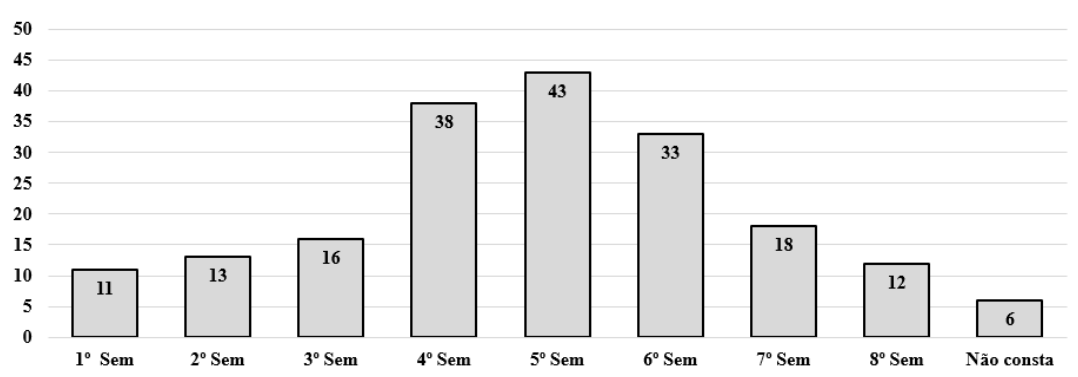

Figura 1 - Períodos das disciplinas de Estatística nas licenciaturas em Matemática. Fonte: Dados da Pesquisa.

Com base no gráfico apresentado na Figura 1, envolvendo a distribuição das disciplinas com conhecimentos de Estatística entre os semestres letivos dos cursos de licenciatura em Matemática no Brasil, identificamos que as disciplinas de Estatística são ofertadas com mais frequência nos $4^{\circ}, 5^{\circ}$ e $6^{\circ}$ períodos; além disso, ressaltamos que em seis PPCs não constam disciplinas que abordam os conhecimentos de Estatística.

Continuando, apresentamos a seguir, na Tabela 4, as doze principais referências bibliográficas utilizadas nos cursos de licenciatura em Matemática das instituições de ensino superior da presente pesquisa.

Tabela 4 - Principais referências bibliográficas da disciplina de Estatística.

\begin{tabular}{clc}
\hline $\mathrm{N}^{\circ}$ & \multicolumn{1}{c}{ Principais Referências Bibliográficas } & $\mathrm{F}$ \\
\hline 1 & FONSECA, J. S. Curso de Estatística. 6. ed. São Paulo: Atlas, 1996. & 44 \\
2 & MEYER, P. L. Probabilidade - Aplicações à Estatística. 2. ed. Rio de Janeiro: Livros Técnicos e & 37 \\
& Científicos Editora, 1983. & 34 \\
3 & TRIOLA, M. Introdução à Estatística. 10. ed. Rio de Janeiro: Livros Técnicos e Científicos, 2009. & 30 \\
4 & SPIEGEL, M. Estatística. Coleção Schaum. Ed. McGraw-Hill. & 25 \\
5 & CRESPO, A. A. Estatística Fácil. 19. ed. São Paulo: Saraiva, 2009. & 25 \\
6 & MAGALHAES E LIMA. Noções de Probabilidade e Estatística. São Paulo: Edusp, 2002. & 17 \\
7 & MORETTIN, L. G. Estatística Básica. Vol. 1. Probabilidade. 7. ed. São Paulo: Makron Books, & 16 \\
8 & HAg9. & 15 \\
9 & MORGAD. S. Fundamentos de Matemática Elementar. Vol. 5. 7. ed. São Paulo: Atual, 2005. C. de O. et. al. Análise combinatória e probabilidade. 9. ed. Rio de Janeiro: SBM, & 15 \\
10 & MARTINS, G.; DONAIRE, D. Princípios de Estatística - 900 Exercícios Resolvidos e Propostos. & 14 \\
11 & BUSSAB, W. O.; MORETTIIN, P. A. Estatística básica. 7. ed. São Paulo: Saraiva, 2011. & 14 \\
12 & MORETTIN, L. G. Estatística Básica - Inferência. V. 2. São Paulo: Makron Books, 1999. & 10 \\
\hline
\end{tabular}
Fonte: Dados da pesquisa.

$\mathrm{Na}$ Tabela 4, verificamos uma carência de referências bibliográficas que prestigiam a construção do conhecimento de Estatística e Probabilidade voltadas à formação de professores de Matemática para Educação Básica. Nesse sentido, destacamos a necessidade de construção e elaboração de livros didáticos cujo foco seja a formação em Estatística nos cursos de licenciatura em Matemática, contribuindo efetivamente para uma formação ampla e crítica do futuro professor.

Prosseguindo, apresentamos a seguir, na Tabela 5, as cargas horárias das disciplinas de Estatística e de Probabilidade nos PPCs dos cursos de licenciatura em Matemática no Brasil 
investigados.

Tabela 5 - Carga horária das disciplinas de Estatística.

\begin{tabular}{ccc}
\hline Carga horária & Quantidade & Frequência relativa \\
\hline Entre 30 e 60 & 52 & $27,30 \%$ \\
Entre 61 e 90 & 79 & $41,70 \%$ \\
Entre 91 e 120 & 25 & $13,10 \%$ \\
Entre 121 e 150 & 19 & $10,00 \%$ \\
Entre 151 e 180 & 05 & $2,70 \%$ \\
Não apresenta & 06 & $3,20 \%$ \\
\hline Total & 190 & $100 \%$ \\
\hline & Fonte: Dados da Pesquisa.
\end{tabular}

Observando a Tabela 5, constatamos que 52 cursos de licenciatura em Matemática possuem no máximo 60 horas para desenvolver os conhecimentos de Estatística na formação inicial dos futuros professores de Matemática, um percentual de apenas $2 \%$ da carga horária total do curso. A nosso ver, essa carga horária destinada aos conhecimentos de Estatística, ofertada nas instituições de ensino superior às quais pertencem os PPCs investigados, é baixa, se considerada a importância desses conhecimentos para a atuação profissional nas escolas dos ensinos fundamental e médio.

Identificamos ainda que existem intervalos que aparecem com mais frequência, como de 61 a 90 horas, com 79 cursos. Apenas 24 cursos de licenciatura em Matemática possuem uma carga horária entre 121 e 180 horas, o que equivale a 12,7\% dos cursos, o que, a nosso ver, é um percentual mais aceitável, em torno de no mínimo $4 \%$ da carga horária dos cursos de formação inicial. Ressaltamos que seis PPCs não possuem disciplinas que abordam os conhecimentos de Estatística em seus cursos de licenciatura em Matemática.

A esse respeito, Viali (2008) enfatiza que a baixa carga horária de tópicos como Estatística e Probabilidade, nos cursos de licenciatura em Matemática no Brasil, provoca um sentimento de despreparo dos licenciados. Complementando, Santos (2005) explicita que é necessário repensar a formação estatística nos cursos de licenciatura em Matemática, pois são eles que formam os professores que lecionarão os conteúdos de Estatística em suas aulas de Matemática nos anos finais dos ensinos fundamental e médio.

\subsection{Procedimentos De Análise De Dados}

Utilizamos, como procedimentos de análise de dados, a Análise de Conteúdo na perspectiva elucidada por Bardin (1977). Segundo a autora, a Análise de Conteúdo corresponde a um conjunto de técnicas de "análise das comunicações, visando obter, por procedimentos objetivos e sistemáticos de descrição do conteúdo das mensagens, indicadores (quantitativos ou 
não) que permitam a inferência de conhecimentos relativos às condições de produção/recepção destas mensagens" (Bardin, 1977, p. 42).

Em relação ao design metodológico da Análise de Conteúdo, inspiramos em Bardin (1977), para explicitar a dinamicidade desse procedimento de análise de dados. Com o corpus da pesquisa constituído, organizamos uma planilha no Excel para fichar as informações referentes aos conhecimentos de Estatística presentes nos PPCs como nos planos de ensino. Dos 190 PPCs analisados, somente 156 continham as ementas. Inicialmente, realizamos o processo de leitura flutuante, que consiste na leitura exaustiva dos dados brutos referentes às ementas que abordam as disciplinas de Estatística nos cursos de licenciatura em Matemática no Brasil. A leitura flutuante tem por objetivo identificar os aspectos que "saltam aos olhos" do pesquisador em relação ao corpus da pesquisa. Bardin (1977, p. 96) destaca que a leitura flutuante "consiste em estabelecer o contato do pesquisador com os documentos da coleta de dados, momento em que se começa a conhecer o texto, deixando-se invadir por impressões e orientações".

As Unidades de Contexto (partes ou trechos significativos das respostas) conduzem à identificação das Unidades de Registro (essência dos recortes das respostas ou depoimentos). As Unidades de Contexto são importantes, pois os trechos (recortes) extraídos das ementas contribuirão como "pano de fundo" para a configuração das Unidades de Registro.

Por Unidade de Registro entende-se “a unidade de significação a codificar e corresponde ao segmento de conteúdo a considerar como unidade de base, visando a categorização" (Bardin, 1977, p. 104). O processo de identificação das Unidades de Registro emana das Unidades de Contexto, que correspondem cada qual à "unidade de compreensão para codificar a unidade de registro e corresponde ao segmento da mensagem, cujas dimensões [...] são óptimas para que se possa compreender a significação exata da unidade de registro" (Bardin, 1977, p. 107). Por utilizarmos "a palavra” como Unidades de Registro, definimos as Unidades de Contexto como sendo as próprias ementas.

Considerando o descrito anteriormente, as Unidades de Registro afloraram a partir da relação temática com o objetivo da presente pesquisa - compreender como as disciplinas de Estatística estão estruturadas nos PPCs de licenciatura em Matemática no Brasil - ou seja, as Unidades de Registro têm por finalidade propiciar uma compreensão do objeto investigado.

As Categorias de Análise são provenientes das articulações com as Unidades de Registro, por meio de um procedimento minucioso de interpretação das similaridades, confluências e divergências. Para a referida autora, o processo de categorização caracteriza-se 
como "uma operação de classificação de elementos constitutivos de um conjunto, por diferenciação e, seguidamente, por reagrupamento segundo gênero (analogia), com os critérios previamente definidos" (Bardin, 1977, p. 117).

Já a interpretação das Categorias de Análise envolve a apresentação de um movimento dialógico entre cada uma delas e o referencial teórico, sob a perspectiva dos objetivos e problemas norteadores da investigação. A seguir, apresentamos o movimento de configuração das Categorias de Análise.

\section{Movimento De Categorização Dos Dados - Análise De Conteúdo}

Neste momento, apresentamos o movimento do processo de categorização dos dados, por meio do procedimento da Análise de Conteúdo (Bardin, 1977).

Para exemplificar, apresentamos no Quadro 2, a seguir, o Movimento de Definição das Unidades de Contexto e Unidades de Registro de duas IES, referentes às ementas das disciplinas de Estatística dos cursos de licenciatura em Matemática.

Quadro 2 - Movimento de Definição das Unidades de Contexto e Unidades de Registro.

\begin{tabular}{|c|c|c|c|}
\hline PPC & Disciplina & Ementas - Unidades de Contexto & Unidades de Registro \\
\hline IFG - & Estatística & 1. Distribuições de Probabilidades; & Probabilidades \\
\cline { 3 - 4 } Goiânia/GO & & 2. Teoria de amostragem; & Amostragem \\
\cline { 3 - 4 } & & 3. Teoria da estimação; & Estimação \\
\cline { 3 - 4 } & & 4. Testes de hipóteses e significância; & Teste de hipóteses \\
\cline { 3 - 4 } & & 5. Regressão e correlação; & Correlação e Regressão \\
\cline { 3 - 4 } & & 6. Análise de variância. & Análise de Variância \\
\hline UNEMAT - & Estatística e & Distribuição de Frequência \\
\hline Burra do & Probabilidade & 1. Distribuição de frequências; & Representação de Dados \\
& & 2. Representação tabular e gráfica; & Estatísticos \\
\cline { 3 - 4 } & & 3. Medidas de tendência central; & Medidas de Posição \\
\cline { 3 - 4 } & & 4. Medidas de dispersão e de variabilidade; & Medidas de Dispersão \\
\cline { 3 - 4 } & & 5. Análise Combinatória; & Análise Combinatória \\
\cline { 3 - 4 } & & 6. Probabilidade. & Probabilidade \\
\cline { 3 - 4 } & &
\end{tabular}

Fonte: Dados da pesquisa.

Com base no exemplo explicitado no Quadro 2, ressaltamos que realizamos o mesmo movimento para definir as Unidades de Registro de cada um dos 190 PPCs de licenciatura em Matemática no Brasil. Assim sendo, o movimento explicitado no Quadro 2 para as 156 ementas dos 190 PPCs nos proporcionou obter uma recorrência de 823 registros, dos quais identificamos 16 Unidades de Registro. Assim, na Tabela 6, apresentamos estas 16 Unidades de Registro e suas respectivas frequências nas disciplinas de Estatística e Probabilidade dos cursos de licenciatura em Matemática no Brasil. 
Tabela 6 - Unidades de Registro das Ementas.

\begin{tabular}{ccc}
\hline $\mathrm{N}$ & Unidades de Registro & Frequência \\
\hline 1 & Medidas de Posição Central & 138 \\
2 & Noções de Probabilidade & 129 \\
3 & Amostragem & 81 \\
4 & Variáveis Aleatórias & 79 \\
5 & Medidas de Dispersão & 78 \\
6 & Distribuição de Frequência & 75 \\
7 & Teste de Hipóteses & 54 \\
8 & Correlação e Regressão & 52 \\
9 & Estimação & 51 \\
10 & Análise Combinatória & 43 \\
11 & Análise de Variância & 18 \\
12 & Noções de estatística inferencial & 15 \\
13 & Construção de tabelas e gráficos estatísticos & 6 \\
14 & Coleta, análise e apresentação dos dados & 2 \\
15 & Estatística na Educação Matemática & 1 \\
16 & História da Estatística e do ensino da Estatística & 1 \\
\hline \multicolumn{4}{c}{ Total } \\
\hline
\end{tabular}

Fonte: Dados da pesquisa.

Tendo em vista as 16 Unidades de Registro descritas na Tabela 6, apresentada acima, mostramos todo o movimento de articulação destas Unidades de Registro em Categorias de Análise, as quais são configuradas por meio de um movimento denominado por Bardin (1977, p. 117) como processo de categorização, que consiste na "classificação de elementos constitutivos de um conjunto, por diferenciação e, seguidamente, por reagrupamento segundo o gênero (analogia), com os critérios previamente definidos".

Buscamos articular as 16 Unidades de Registro por similaridades e convergências temáticas, o que exigiu uma leitura cuidadosa das mesmas. Ao final deste processo, articulamos todas as Unidades de Registro em quatro Categorias de Análise, as quais apresentamos, a seguir, no Quadro 3.

Quadro 3 - Articulação das Unidades de Registro em Categorias de Análise.

\begin{tabular}{|c|c|}
\hline Unidades de Registro & Categoria de Análise \\
\hline Medidas de Posição Central & \multirow{4}{*}{ Estatística Descritiva } \\
\hline Amostragem & \\
\hline Distribuição de Frequência & \\
\hline Medidas de Dispersão & \\
\hline Variáveis Aleatórias & \multirow{6}{*}{ Estatística Inferencial } \\
\hline Noções de estatística inferencial & \\
\hline Estimação & \\
\hline Teste de Hipóteses & \\
\hline Correlação e Regressão & \\
\hline Análise de Variância & \\
\hline Noções de Probabilidade & \multirow{2}{*}{$\begin{array}{c}\text { Probabilidade e Análise } \\
\text { Combinatória }\end{array}$} \\
\hline Análise Combinatória & \\
\hline Estatística na Educação Matemática & \multirow{4}{*}{$\begin{array}{c}\text { Ensino de Estatística na Educação } \\
\text { Básica }\end{array}$} \\
\hline História da Estatística e do ensino da Estatística & \\
\hline Construção de tabelas e gráficos estatísticos & \\
\hline Coleta, análise e apresentação dos dados & \\
\hline
\end{tabular}

Fonte: Dados da Pesquisa. 
Em todo o processo de codificação dos dados brutos envolvendo as ementas das disciplinas de Estatística por meio de confluências e divergências entre as Unidades de Registro, para relacionarmos com as Categorias de Análise, identificamos que as 16 Unidades de Registro convergiram, o que nos conduziu a quatro Categorias de Análise, a saber: (i) Estatística Descritiva; (ii) Estatística Inferencial; (iii) Análise Combinatória e Probabilidade; (iv) Ensino de Estatística na Educação Básica.

\section{Análise Interpretativa Das Categorias}

Neste momento, apresentamos a interpretação das Categorias de Análise da pesquisa, por meio de um movimento dialógico - interlocução dos dados com os conceitos balizados pelos aportes teóricos da pesquisa -, para nos proporcionar compreensões dos conteúdos das ementas da disciplina de Estatística dos cursos de licenciatura em Matemática com a prática dos futuros professores de Matemática na Educação Básica.

Ressaltamos que o movimento dialógico envolve os recortes dos PPCs com a literatura pertinente, articulando-os às referências teóricas e ainda às nossas percepções. Assim sendo, a relação entre os dados obtidos e a fundamentação teórica é que dará sentido à nossa interpretação. A análise das categorias foi contemplada individualmente, para verificar sua importância nos cursos de licenciatura em Matemática na disciplina de Estatística.

Iniciamos o movimento dialógico interpretativo da primeira Categoria de Análise, denominada: Estatística Descritiva, a qual foi constituída por quatro Unidades de Registro, denominadas: (i) Medidas de Posição Central (138 registros); (ii) Amostragem (81 registros); (iii) Distribuição de Frequência (75 registros); (iv) Medidas de Dispersão (78 registros). Assim sendo, identificamos 372 registros (o que equivale a 45,2\% do total de 823 registros) referentes à Estatística Descritiva nas ementas das disciplinas que abordam a formação estatística nos PPCs.

Consideramos que os conteúdos de Estatística Descritiva devem ser trabalhados nos cursos de licenciatura em Matemática, para que os futuros professores tenham conhecimentos de como abordá-los para os alunos dos ensinos fundamental e médio. A esse respeito, Correa (2003, p. 9) afirma que a "Estatística descritiva e a amostragem constituem no conjunto de técnicas que objetivam coletar, organizar, apresentar, analisar e sintetizar os dados numéricos de uma população, ou amostra".

Lopes (2008), ao apresentar recomendações para o ensino de Estatística e Probabilidade 
no currículo de Matemática, bem como para a formação inicial e continuada dos professores de Matemática, declara que:

[...] os professores precisam possuir conhecimentos sobre a matéria que ensinam, conheçam o conteúdo em profundidade, sendo capazes de organizá-lo mentalmente, de forma a estabelecer inúmeras inter-relações, relacionem esse conteúdo ao ensino e à aprendizagem, em um processo de interação com os alunos, considerando o desenvolvimento cognitivo dos mesmos e, também, dominem o contexto, tendo clareza do local em que ensinam e a quem ensinam (Lopes, 2008, p. 65).

Complementando, a referida pesquisadora explicita que é "essencial à formação de nossos alunos o desenvolvimento de atividades estatísticas que partam sempre de uma problematização, pois assim como os conceitos matemáticos, os estatísticos também devem estar inseridos em situações vinculadas ao cotidiano deles" (Lopes, 2008, p. 58).

Com base nos autores mencionados, podemos afirmar que são fundamentais, para a formação dos futuros professores de Matemática, os conteúdos de Estatística Descritiva, no entanto, os professores formadores atuantes nas licenciaturas em Matemática das IES devem se atentar para não ministrar os conteúdos de uma maneira desconectada da realidade ou abordar tais assuntos superficialmente sem uma preocupação em como ensinar esses conteúdos.

A segunda Categoria de Análise, denominada: Estatística Inferencial, foi constituída por seis Unidades de Registro, denominadas: (i) Variáveis Aleatórias (79 registros); (ii) Teste de Hipóteses (54 registros); (iii) Correlação e Regressão (52 registros); (iv) Estimação (51 registros); (v) Análise de Variância (18 registros); e (vi) Noções de estatística inferencial (15 registros). Assim sendo, identificamos 269 registros (o que equivale a 32,6\% do total de 823 registros) referentes à Estatística Inferencial nas ementas das disciplinas que abordam a formação estatística nos PPCs.

Considerando a baixa carga horária destinada aos conteúdos de Estatística nos cursos de licenciatura em Matemática e também a necessidade de uma articulação entre os conteúdos da formação inicial e a futura prática pedagógica, questionamos: nossos cursos de licenciatura em Matemática estão preparando os futuros professores de Matemática para ensinar conceitos e conteúdos de Estatística e ainda desenvolver as competências estatísticas nos alunos da Educação Básica?

A partir de nossa análise às ementas das disciplinas de Estatística, notamos que existem indícios de que nossos cursos de licenciatura em Matemática não estão preparando os futuros professores de Matemática para ensinar conceitos e conteúdos de Estatística nas escolas da Educação Básica. Assim sendo, apesar de considerarmos essencial os futuros professores de Matemática terem uma compreensão dos conteúdos de Estatística Inferencial, a realidade é que 
nossos cursos devem priorizar os conceitos de Estatística que os futuros professores terão que ensinar na Educação, como aborda Lopes (2013, p. 905):

O ensino de estatística em um curso de licenciatura de matemática precisa, não apenas, ter o quê, o porquê, o quem e o quando, mas, essencialmente, o como. Apesar de muito se ter discutido nos últimos anos sobre como os alunos devem aprender estatística, é necessário pensar como nós, os professores, podemos ser mais eficazes em promover a aprendizagem de nossos estudantes.

Com base na problemática levantada, nossa proposição vai ao encontro do apresentado por Lopes (2013), pois entendemos que primeiramente as disciplinas de Estatística nos cursos de licenciatura em Matemática devem contemplar o estudo das competências estatísticas, bem como proporcionar aos futuros professores de Matemática que exercitem a sua capacidade de desenvolver atividades para a sala de aula, a fim de promover a aprendizagem estatística nos alunos da Educação Básica.

A terceira Categoria de Análise, denominada: Probabilidade e Análise Combinatória, foi constituída por duas Unidades de Registro, denominadas: (i) Noções de Probabilidade (129 registros); Análise Combinatória (43 registros). Assim sendo, identificamos 172 registros (o que equivale a $20,9 \%$ do total de 823 registros) referentes à Probabilidade e Análise Combinatória nas ementas das disciplinas que abordam a formação estatística nos PPCs.

Levando em conta os aspectos destacados nas ementas apresentadas anteriormente, detectamos que esses conteúdos são recorrentes na disciplina de Estatística e Probabilidade, e podemos afirmar que esses conteúdos (Probabilidade e Análise Combinatória) são importantes para a atuação profissional do futuro professor de Matemática, pois são conteúdos que devem ser ministrados nas aulas de Matemática dos ensinos fundamental e médio.

Em relação ao ensino de Probabilidade na Educação Básica, Bernardes (1987, p. 13) enfatiza que "o ensino da Matemática se deve ocupar mais da tomada consciente de decisões do que do estrito cálculo, então a teoria das probabilidades é fundamental”. Já em relação ao ensino de Análise Combinatória, Pinheiro e Sá (2010) declaram que os professores de Matemática atuantes nas escolas não tiveram uma formação consistente em relação à Análise Combinatória, pois:

Encontram-se fragilizados pela formação inicial que só considerava importante o profundo conhecimento matemático em detrimento das questões metodológicas para o ensino dos tópicos da matemática, estudados nas escolas. Com isso, eles procuram desenvolver um ensino de Análise combinatória apresentando a definição, seguida de exemplos e exercícios de fixação. Ou seja, sem proporcionar um caminho metodológico que leve os alunos ao desenvolvimento do raciocínio combinatório (Pinheiro \& Sá, 2010, p. 9).

Considerando as dificuldades dos professores em ensinar e dos alunos em aprender 
Análise Combinatória nas escolas da Educação Básica, podemos inferir que esse quadro negativo é reflexo de que a formação inicial dos futuros professores de Matemática nos cursos de licenciatura não tem sido suficiente para proporcionar os conhecimentos básicos para eles ensinarem o conteúdo de Análise Combinatória.

Na nossa visão, com as reformulações da Base Nacional Comum Curricular - BNCC dos conteúdos de Matemática para os ensinos fundamental e médio, os cursos de licenciatura em Matemática no Brasil devem reformular seus PPCs, para que exista uma disciplina específica de Probabilidade e Análise Combinatória na formação inicial, pois os futuros professores de Matemática precisam possuir o domínio conceitual dos referidos conteúdos, bem como o conhecimento pedagógico de como ensiná-los na Educação Básica. Assim sendo, para nós, é indispensável que na formação inicial do futuro professor de Matemática ocorra um maior contato deste com o processo de ensino e aprendizagem de Probabilidade e Análise Combinatória, conscientizando-o da relevância deste conteúdo na formação de seus alunos.

Com base no explicitado, compreendemos a importância de os professores de Matemática em serviço trabalharem na Educação Básica os conteúdos de Probabilidade e Análise Combinatória, na perspectiva da resolução de problemas, e de maneira intuitiva, proporcionando oportunidades para os alunos resolverem problemas de forma criativa e crítica, sem o uso excessivo de fórmulas. No entanto, que isso só será possível se, nos cursos de licenciatura em Matemática, os futuros professores de Matemática tenham vivências formativas envolvendo a prática de ensino dos conteúdos de Probabilidade e Análise Combinatória.

A quarta Categoria de Análise, denominada: Ensino de Estatística na Educação Básica, foi constituída por quatro Unidades de Registro, denominadas: (i) Estatística na Educação Matemática (1 registro); História da Estatística e do ensino da Estatística (1 registro); Construção de tabelas e gráficos estatísticos (6 registros); Coleta, análise e apresentação dos dados ( 2 registros). Assim sendo, identificamos 10 registros (o que equivale a 1,2\% do total de 823 registros), referentes ao Ensino de Estatística na Educação Básica nas ementas das disciplinas que abordam a formação estatística nos PPCs.

É isso mesmo: identificamos que apenas 1,2\% das ementas das disciplinas que abordam a formação estatística nos PPCs explicitam a importância de trabalhar na licenciatura em Matemática um ensino de Estatística pensando na futura prática pedagógica dos professores de Matemática na Educação Básica, uma vez que "é necessário que a escola traga para si a responsabilidade de introduzir e desenvolver o conhecimento estatístico com seus alunos, objetivando formar cidadãos capazes de ler, compreender e comparar dados estatísticos, bem 
como criticá-los" (Cazorla et al., 2008, p. 2).

Encontramos apenas uma disciplina, entre 190 disciplinas consultadas, que evidencia o desenvolvimento de ações e intervenções pedagógicas nos ensinos fundamental e médio envolvendo os conteúdos de Estatística, no sentido de proporcionar oportunidades para os futuros professores de Matemática trabalharem com uma abordagem metodológica diferenciada em sala de aula com os alunos da Educação Básica.

Sobre isso, Lopes (2008, p. 66) declara que, na formação do professor de Matemática, "faz-se necessária uma combinação adequada entre conhecimento sobre o conteúdo matemático a ser ensinado e o conhecimento pedagógico e didático de como ensiná-lo". Além disso, Damin, Junior e Pereira (2016, p. 267) explicitam que os professores formadores atuantes na disciplina de Educação Estatística nas licenciaturas em Matemática devem trabalhar com os futuros professores, para que eles tenham a capacidade de analisar atividades, materiais, recursos e abordagens disponíveis para o ensino de Estatística, visando a sua futura atuação na Educação Básica de uma maneira efetiva, de modo a tornar-se um educador estatístico.

\footnotetext{
Entende-se que um educador estatístico é o professor de Matemática que tenha domínio de conceitos e conteúdos estatísticos e saiba relacioná-los com a sua prática pedagógica. Espera-se ainda, que o educador estatístico possa proporcionar essas atividades num contexto significativo para o aluno, tornando-o crítico e que saiba se comunicar utilizando as terminologias estatísticas, isto é, auxiliando a desenvolver as competências estatísticas, a saber, o letramento, o raciocínio e o pensamento estatístico (Damin, Junior \& Pereira, 2016, p. 267).
}

Com base nos aspectos apontados na presente pesquisa, podemos inferir que os futuros professores de Matemática estão concluindo seus processos de formação inicial nos cursos de licenciatura em Matemática sem o devido preparo para ensinar conceitos e conteúdos de Estatística, e muito menos para desenvolverem as competências estatísticas nos alunos da Educação Básica, conforme apontado pela BNCC.

Assim sendo, compactuamos com Costa e Pamplona (2011, p. 899) quando enfatizam a necessidade de criação de uma disciplina de Educação Estatística nas licenciaturas em Matemática no Brasil, pois "a atual conjuntura aponta a necessidade de transformação da licenciatura, de modo que ela possa oferecer referências a partir das quais os estudantes dela egressos de fato estruturem suas práticas de Educação Estatística na Educação Básica".

Na nossa visão, a implementação de uma disciplina denominada "Educação Estatística" nas licenciaturas em Matemática atenuaria o distanciamento existente entre a formação proporcionada pelos cursos de formação inicial e a futura prática pedagógica na Educação Básica, em relação ao processo de ensino e aprendizagem de Estatística. 


\section{Considerações Finais}

Com base nos aspectos explicitados no presente artigo, compreendemos que existe a necessidade de um redimensionamento dos conteúdos existentes nas ementas das disciplinas de Estatística dos cursos de licenciatura em Matemática, objetivando constituir uma proposta de ensino de Estatística na formação inicial do professor de Matemática para a Educação Básica, com foco na construção do pensamento estatístico dos alunos, futuros cidadãos e profissionais das mais diversas áreas.

A partir dos dados explicitados, identificamos que as disciplinas de Estatística possuem uma baixa carga horária nos cursos de licenciatura em Matemática. Assim sendo, podemos inferir que licenciandos em Matemática estão saindo dos cursos de formação inicial sem o domínio conceitual de conteúdos de Estatística, fato esse que prejudicará o desenvolvimento desses conhecimentos em suas práticas nas aulas na Educação Básica.

Notamos que a maneira como a disciplina de Estatística está inserida nos cursos de licenciatura em Matemática tem se revelado insuficiente, o que pode provocar, nos professores de Matemática em serviço nas escolas, uma insegurança em trabalhar com os conteúdos de Estatística nos ensinos fundamental e médio, ou simplesmente trabalhar apenas de maneira algorítmica, o que dificulta o desenvolvimento do pensamento estatístico dos alunos.

Com base nos dados, documentos oficiais e pesquisas recentes que abordam o ensino de Estatística, concluímos a presente pesquisa ampliando o "coro" pela necessidade de se implementar uma disciplina de Educação Estatística para os anos finais do ensino fundamental nas licenciatura em Matemática em atividade no Brasil, pois, da maneira como as disciplinas de Estatística estão estruturadas na matriz curricular, não tem sido suficiente para proporcionar os conhecimentos básicos e muito menos metodológicos para que os futuros professores de Matemática tenham domínio conceitual e pedagógico das diferentes maneiras de ensinarem os conteúdos de Estatística em suas aulas na Educação Básica.

Finalizando, afirmamos que as inferências explicitadas na presente pesquisa, a partir da sistematização e tratamento de dados coletados junto aos 190 PPCs de licenciatura em Matemática em atividade no Brasil, podem ser consideradas como proposições para que os NDEs rediscutam e redefinam o foco dos conhecimentos de Estatística desenvolvidos na formação inicial. 


\section{Referências}

Bardin, L. (1977). Análise de conteúdo. Lisboa: Edições 70, 1977.

Bernardes, O. (1987). Para uma abordagem do conceito de probabilidade. Educação \& Matemática, Lisboa, n. 3.

Cazorla, I. M. et al. (2008). A leitura e interpretação de gráficos e tabelas no ensino fundamental e médio. Anais do $2^{\circ}$ SIPEMAT. Recife, PE.

Correa, S. M. B. B. (2003). Probabilidade e Estatística. 2. ed. Belo Horizonte: PUC Minas Virtual, $116 \mathrm{p}$.

Costa, A. (2007). A educação estatística na formação do professor de matemática. 153 f. Dissertação (Mestrado em Educação) - Universidade São Francisco, Itatiba, SP.

Costa, W. N. G.; Pamplona, A. S. (2011). Entrecruzando Fronteiras: a Educação Estatística na formação de Professores de Matemática. Bolema, Rio Claro, SP, v. 24, n. 40, p. 897-911.

Creswell, J. W. (2007). Projeto de pesquisa: métodos qualitativo, quantitativo e misto. Tradução: Luciana de Oliveira da Rocha. 3. ed. Porto Alegre: Artmed.

Damin, W.; Junior, G. S.; Pereira, R. S. G. (2016). Educação Estatística e os Currículos das Licenciaturas em Matemática. Vivências, v. 12, n. 22, p. 263-273.

Gatti, B. A. (2002) A construção da pesquisa em educação no Brasil. Brasília: Plano.

Gil, A. C. (2002). Métodos e técnicas de pesquisa social. 5. ed. São Paulo: Atlas.

Lopes, C. E.; Coutinho, C.; Almouloud, S. A. (Org.). (2010). Estudos e reflexões em Educação Estatística. Campinas, SP: Mercado de Letras.

Lopes, C. E. (2013). Educação Estatística no curso de licenciatura em matemática. Bolema, v. 27, n. 47, p. 901-915, 2013.

Lopes, C. E. (2008). O ensino de probabilidade e estatística na educação básica e a formação de professores. Caderno Cedes, Campinas, SP, v. 28, n. 74, p. 57-73.

Pinheiro, C. A. M; Sá, P. F. (2010). Uma Proposta de Ensino de Análise Combinatória. Belém: SBEM-PA, (Coleção Educação Matemática da Amazônia, v. 2).

Santos, C. R. (2005). O tratamento da informação: Currículos prescritos, formação de professores e implementação em sala de aula. Dissertação (Mestrado Profissional) Pontifícia Universidade Católica de São Paulo, São Paulo.

Silva, L. B. (2014). A Estatística e a Probabilidade nos Currículos dos Cursos de Licenciatura em Matemática no Brasil. 129 f. Dissertação (Mestrado em Educação Matemática e Tecnológica) - Universidade Federal de Pernambuco, Recife, PE. 
Silva, M. A. (2011). A Presença da Estatística e da Probabilidade no Currículo Prescrito de Cursos de Licenciatura em Matemática: uma análise do possível descompasso entre as orientações curriculares para a Educação Básica e a formação inicial do professor de Matemática. Bolema, Rio Claro, SP, v. 24, n. 40, p. 747-764.

Viali, L. (2008). O ensino de Estatística e Probabilidade nos cursos de Licenciatura em Matemática. XVIII SINAPE (Simpósio Nacional de Probabilidade e Estatística). São Pedro/SP.

Viali, L.; Cury, H. N. (2011). Professores de matemática em formação continuada: uma análise de erros em conteúdos de Probabilidade. EM TEIA - Revista de Educação Matemática e Tecnológica Ibero-Americana, v. 1, n. 1. 